\title{
Análisis de la septicemia bacteriana en el neonato en los últimos cinco años en el Servicio de Pediatría del Hospital Regional Leonardo Guzmán, de Antofagasta
}

\author{
Drs. J. Manuel Yáñez Z.,' Manuel Zamorano G., ${ }^{1}$ Carmen DYaz Q., ${ }^{2}$ Paulino Guerra A. ${ }^{2}$
}

\begin{abstract}
The clinical records of 15 neonates with septcemia confirned by becterial isolation were analysed at the Leonardo Guzmán Hospital, Antolagasto, between 1974 and 1978.

In that period 19.018 infants were bom, 1.883 weighted less than 2.500 grams. 41 patients were clinically suspected to have some kind of infection, which was demonstrated by cultures in 15 ( 7 preterm and 8 term infants).

Gram negative onganisms of the Aenobacter/Klebsiella group were identified in 13 patients. Sigas and symptoms were simular to those described in literature. Leucocite differential counts showed left ward deviation in 8 cases and $20 \%$ bacilliform in 7. $26,7 \%$.

The most widely used antibiotic was Centanicin, combined with same kind of Penicillin. Lethality was

Some suggestions are made to improve diagnosis.
\end{abstract}

La septicemia bacteriana neonatal, definida como una infección generalizada del neonato documentada por uno o más hemocultivos positivos, ${ }^{1}$ es un cuadro frecuente en los Servicios de Recién Nacidos y Premahuros.

Su incidencia real es difícil de establecer, debido a la inespecificidad semiológica del recién nacido y las dificultades para la corroboracion bacteriológica del cuadro, fluctuando las cifras de autores extranjeros entre 1 - 1,8 $\times 1.000$ nacidos vivos, cuando el criterio diagnóstico es bacteriológico. ${ }^{\text {. }}$ 2, 3

En nuestro medio, en 1974 en el Hospital Félix Bulnes, Zelada encuentra una incidencia de sepsis y meningitis neonatal de $7,7 \times 1.000$ nacidos vivos. ${ }^{4}$

Si su incidencia se establece solamente basándose en la sospecha clínica, este puede subir a cifras tan altas como el $20 \% .^{1}$

La frecuencia y gravedad de las infecciones en el recién nacido se ve favorecida por la inmadurez del sistema inmunológico propio de esta edad, junto a una mayor exposición al riesgo (RPM, maniobras agresivas diagnósticas o terapéuticas, estada intrahospitalaria prolongada). Estas condjciones se acentúan en el recién nacido de bajo peso, especialmente en el pretérmino, mencionándose cifras de incidencia de sepsis de $164 \times$

IMédicos Grupo Especialidades, Departarnento Ciencias de la Salud, Universidad de Chile, Sede Antofagasta.

${ }^{2}$ Médicos Servicio Pediatrín, Unidad Veonatologia, Hospital Regional Leonardo Guzmán, de Antofagasta.
1.000 nacidos vivos en pretérminos de 1.001 $1.500 \mathrm{~g}$ de peso de nacimiento.

La etiología ha variado en el curso de los años, siendo inicialmente el agente predominante el estreptococo B hemolítico grupo A (década 30 40), luego el estafilococo (década 50) y posteriormente los gérmenes Gram (-), los que han predominado hasta la actualidad. ${ }^{6,7}$ Recientemente la literatura extranjera ha comunicado numerosos casos de infecciones neonatales graves causadas por estreptococos $\mathrm{B}$ bemolíticos grupo $\mathrm{B},{ }^{8}$ mientras que a nivel nacional solamente se han comunicado 2 casos de meningitis neonatal por este germen. ${ }^{9}$

La letalidad, si bien es cierto ha disminuido desde alrededor de un $90 \%$ antes de 1937 , continúa siendo alta con cifras actuales que oscilan entre 13 y $42 \% .^{6}$

Dada la importancia y gravedad de esta patología, es que nos interes $\delta$ revisar nuestra experiencia de los últimos cinco años.

\section{MATERIAL Y METODO}

Se analizan las historias clínicas de 15 recién nacidos hospitalizados entre los años 1974 y 1978 inclusive, en la Unidad de Prematuros y Recién Nacido Patológico del Servicio de Pediatria del Hospital Regional Dr. Leonardo Guzmán, de Antofagasta, en los cuales se efectuó el diagnóstico de septicemia.

El diagnóstico se fundamentó en la existencia de un cuadro clínico compatible y el hallazgo bac- 
teriológico en el hemocultivo u otra secreción confiable.

Se revisó la incidencia del cuadro en la Unidad, la correlación entre la sospecha clínica y su corroboración de laboratorio, el tipo de parto, el APGAR al minuto, el sexo y la edad gestacional. Además se consignó la etiologia, los hallazgos semiológicos y hematológicos, la duración de la hospitalización, el tratamiento antibiótico y la letalidad.

\section{RESULTADOS}

Durante los años 1974 y 1978 nacieron en la Maternidad del Hospital Pegional Dr. Leonardo Guzmán, de Antofagasta, 19.018 niños, de los cuales $2.538(13,3 \%)$ ingresaron a la Unidad de Premahuros y Recién Nacido Patologico por alguna enfermedad o condición que necesitaba algún cuidado especial. En $\mathbf{4 1}$ de estos niños se sospechó clínicamente la infección, lo que corresponde a 2,1\% recién nacidos vivos, pudiendo comprobarse la sepsis por el estudio bacteriológico solamente en 15 casos $(0,8 \%$ nacidos vivos).

De los 15 recién nacidos en los cuales se comprobó la septicemia, 8 tenían antecedentes de parto eutóxico, 5 nacieron por operación cesárea y 2 en presentación podálica.

El APGAR efectuado al minuto de vida fue superior a 7 en 7 casos, entre 4 y 6 en 5 casos, menor de 3 en 1 caso, y no se pudo obtener el dato en 2 casos.

En cuanto al sexo, no hubo mayor diferencia, ya que nuestro grupo de estudio lo constituyeron 8 hombres y 7 mujeres.

Igual cosa ocurrió en la edad gestacional, ya que 8 recién nacidos eran de término y 7 de pretérmino. (Tabla 1.)

Table 1

Frecuencia según sexo y edad gestacional en 15 casos de septicemia neonatal

\begin{tabular}{|c|c|c|c|}
\hline \multirow{2}{*}{ EDAD GESTACIONAL } & \multicolumn{2}{|c|}{ SEXO } & \multirow{2}{*}{$\begin{array}{c}\text { TOTAL } \\
\text { AMBOS SEXOS }\end{array}$} \\
\hline & MASCULINO & FEMENINO & \\
\hline Pretérmino & 3 & 4 & 7 \\
\hline Término & 5 & 3 & 8 \\
\hline T OTA L & 8 & 7 & 15 \\
\hline
\end{tabular}

Cabe destacar que durante el periodo de estudio nacieron en nuestro hospital 1.883 niños de menos de $2.500 \mathrm{~g}$ y 17.135 con más de $2.500 \mathrm{~g}$.

Al no disponer del número exacto de recién nacidos pretérmino, se puede utilizar este dato como cifra aproxínada (a riesgo de considerar pretérminos algunos R.N.T. pequeños para la edad gestacional y no considerar a otros que, siendo pretérminos, son grandes para la edad gestacional), lo cual nos da una incidencia, para los recién nacidos de término, de $0,47 \%$ nacidos vivos, $y$ para los recién nacidos pretérmino una incidencia de $3,7 \%$ nacidos vivos.

Como se ve en la Tabla 2 , en 13 casos $(86,7 \%)$ se identificaron gérnenes gram negativos, ocupando el primer lugar el grupo Klebsiella/Aerobacter, con 8 pacientes $(53,3 \%)$. Los 2 casos en los que el agente etiológico fue el estafilococo aureus tuvieron la particularidad de presentarse en 1974.

Tabla 2

Distribución según frecuencia de los gérmenes encontrados en 15 recién nacidos con septicemia

\begin{tabular}{lcc}
\hline \multicolumn{1}{c}{ GERMEN } & N. CASOS & $\%$ \\
\hline Klebsiella/Aerobacter & 8 & 53,3 \\
Pseudomonas & 2 & 13,3 \\
Estafilococo aureus & 2 & 13,3 \\
E. Coli & 1 & 6,7 \\
Citrobacker Freundii & 1 & 6,7 \\
Proteus Mirabilis & 1 & 6,7 \\
\hline \multicolumn{1}{c}{ TOTAL } & 15 & 100,0 \\
\hline
\end{tabular}


Estos gérmenes fueron aislados de hemocultivos, excepto en 2 casos; en uno de estos niños, que posteriormente falleció, se aislo estafilococo dorado en muestra de pus umbilical, y en el otro caso se ajsló Pseudomona simultáneamente en secreción faríngea, coprocultivo, secreción nasal y se- creción de pústulas.

Los signos y síntomas se presentan en Gráfico N. ${ }^{\circ}$ l, predominando los trastomos respiratorios, el decaimiento y las alteraciones de la termomegulación.

\section{Grâfico $\mathbf{N}^{\circ} 1$}

Síntomas y signos según frecuencia en 15 recién nacidos con septicemia

N. ${ }^{\circ}$ de casos

Trastornos respiratorios

Decaimiento

Alt. Temorregulación

Ictericia

Palidez

Diarrea

Hepatomegalia

Anorexia

Alt. tonicidad

Esplenomegalia

Hemorr. (pie)-mucosas)

Abscesos cutńneos y pústulas

Vómitos

Escleredema

Deshidratación

Necrosis cutánea

Onfalitis

Comp. de conciencia

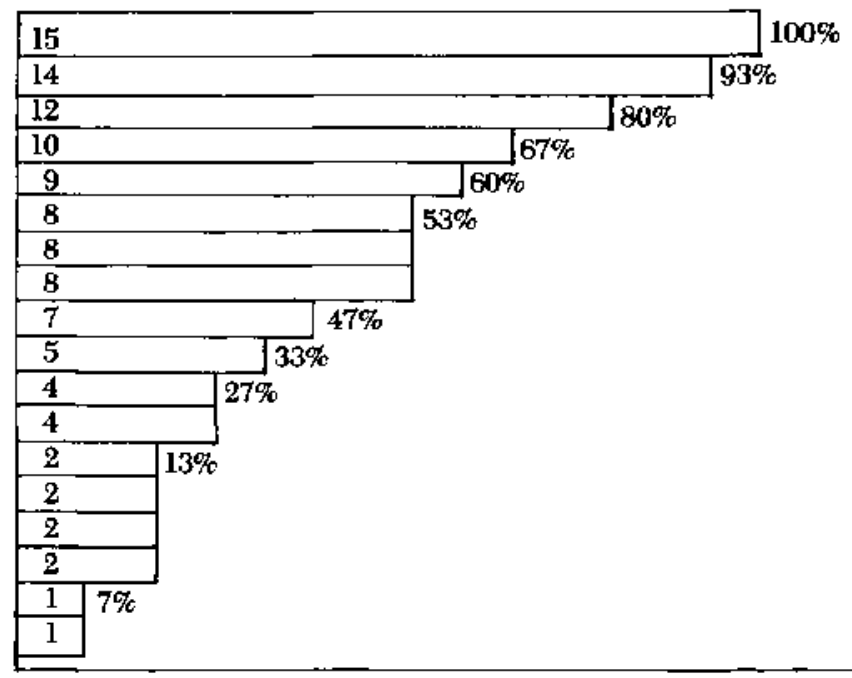

El hemograma se realizó en 12 pacientes, comprobándose desviación a izquierda con más de 500 baciliformes por $\mathrm{mm}^{3}$ en 8 casos $(53,3 \%)$.

Al relacionar la cifra de baciliformes con el número total de neutrófilos, se obtuvieron porcentajes superiores a $20 \%$ sólo en 7 casos.
Días de estada: el promedio de hospitalización fue de 36 días, con un rango de 4 a 91 días.

Tratamiento: se utilizó un promedio de 3 antibióticos por niño, siendo el más empleado la Gentamicina asociada con alguna penicilina. (Gráfico N. ${ }^{\circ}$.)

\section{Grafico N ${ }^{\circ} 2$}

Antibióticos usados en 15 recién nacidos con septicemia

Duración promedio

del tratamiento

Gentamicinā

Cloxacilina

Penicilina

Ampicilina

Kanamicina

Sisomicina

Carbenicilina

Neomicina

Cotrimoxazol

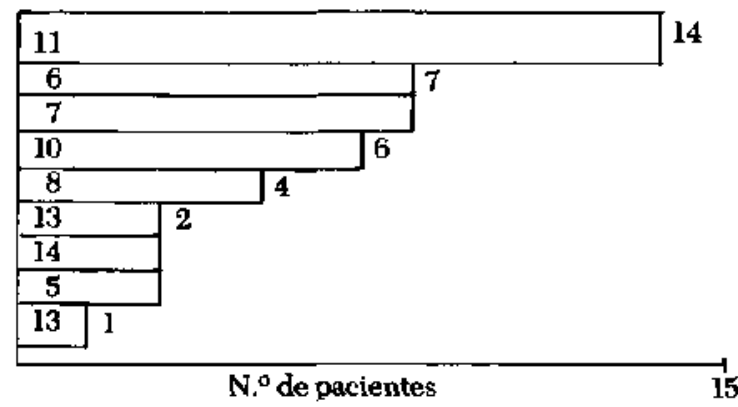


La letalidad global fue de $26,7 \%$ ( 4 casos), destacándose el hecho que todos los fallecidos eran de término y que el $75 \%$ ( 3 casos) eran niños provenientes de sus hogares que tenian más de una semana de edad al ingresar al Servicio.

Al revisar la letalidad según etiologia (Tabla 3 ), destaca el hecho que los $\mathbf{2}$ casos de etiología estafilacócica fallecieron, 1 de los 2 casos producidos por Pseudomonas también falleció y sólo 1 de los 8 casos producidos por Klebsiella/Aerobacter falleció.

Tabla 3

Letalídad según etiologia en $\mathbf{1 5}$ casos de recién nacidos con septicemia

\begin{tabular}{lccc}
\hline ETIOLOGIA & N. ${ }^{\circ}$ DE CASOS & N. FALLECIDOS & $\begin{array}{c}\text { LETALIDAD } \\
\%\end{array}$ \\
\hline KJebsiella/Aerobacter & 8 & 1 & 12,5 \\
Estafilococo aureus & 2 & 2 & 100,0 \\
Pseudomona & 2 & 1 & 50,0 \\
E. Coli & 1 & 0 & 0,0 \\
C. Freundii & 1 & 0 & 0,0 \\
P. Mirabilis & 1 & 0 & 0,0 \\
\hline \multicolumn{1}{c}{ TOTAL } & 15 & 4 & 26,7 \\
\hline
\end{tabular}

\section{DISCUSION}

La septicemia bacteriana neonatal es un cuadro poco frecuente en la Unidad de Prematuros y Recién Nacido Patológico del Servicio de Pediatría del Hospital Dr. Leonardo Guzmán, de Antofagasta, con una incidencia de $0,8 \%$ o nacidos vivos, cercana a las mejores estadísticas extranjeras. Esta incidencia aumenta al $2,1 \%$ nacidos vivos, si se consideran todos los casos en los cuales hubo el diagnóstico clínico de sepsis, incluyendo aquellos en los cuales no se logró la comprobación bacteriológica de la infección.

La incidencia es notoriamente mayor en los recién nacidos pretérmino que en los recién nacidos de término $(3,7 \%$ contra $0,47 \%$ ) .

En nuestra pequeña casuística no hubo predominio de parto distócico, lo cual es considerado un factor de riesgo de infección bacteriana neonatal. ${ }^{7}$, 10,11

De igual manera, no hubo predominio de] sexo masculino sobre el femenino, como se ha comunicado frecuentemente, estableciéndose una relación cercana a 1 : 1 entre ambos sexos.

La etiología predominante en nuestros 15 casos concuerda con la encontrada en otras series, con predominio de gérmenes gram negativos, ${ }^{6,7.11}$ y especialmente con una reciente revisión nacional sobre el tema, ocupando el ler. lugar la KlebsieIla/Aerobacter. ${ }^{12}$

Los signos y síntomas se presentaron de acuerdo a lo descrito en la literatura.

El hemograma, que actualmente es considerado un elemento valioso en el diagnóstico de la infección grave del neonato, ${ }^{1}, 13,14$ en nuestra serie no tuvo el rendimiento esperado, situación que nosotros explicamos por el hecho de que en la mayoría de los casos solamente se tomó una muestra y en diferentes momentos de la evolución de la enfermedad.

La letalidad de $26,7 \%$ fue notoriamente inferior a la comunicada por otros autores, ${ }^{6,7,10,14}$ pero sigue siendo extremadamente alta, lo cual hace pensar en la necesidad de contar con elementos que permitan efectuar un diagnóstico precoz para instaurar un tratamiento especifico oportuno.

Al respecto llama la atención, al revisar.la litteratura actual, cómo algunos exámenes de laboratorio de fácil ejecución permiten evaluar el riesgo de infección, por un lado, y plantear precozmente el diagnóstico de sepsis, por otro. ${ }^{4}{ }^{13}$, 14, 15 Estos exámenes (recuento de polimorfonucleares en líquido amniótico del conducto auditivo externo, microsedimentación, hemograma seriado) deben ser efectuados oportumamente para que tengan rendimiento. 
Creemos que si a lo anterior se agrega una actitud de vigilancia clínica concienzuda, muchas veces realizada por el personal de Enfermeria que maneja al neonato, y se valoran ordenadamente los signos y sintomas precoces de infección, es posible que logremos mejorar el pronostico que tiene el recién nacido frente a la agresión bacteriana,

\section{RESUMEN}

Se analizan las historias clínicas de 15 neonatos con Septicemia comprobada bacteriológicamente, hospitalizados entre 1974 y 1978 en el Hospital Dr. Leonardo Guzmán, de Antofagasta.

En este período nacen 19.018 niños, de los cuales 1.883 pesan menos de $2.500 \mathrm{~g}$. En $41(2,1 \%$ ) se plantea la sospecha clínica de infección, la cual se comprueba mediante aislamiento del gemen en 15 casos $(0,8 \%)$, de los cuales 7 corresponden a pretérminos $(3,7 \%$ ) y 8 a témino $\langle 0,47 \%$ ) .

Ocho niños nacen por parto nomal y el resto corresponde a algún tipo de distocia.

El APGAR al minuto es superior a 6 en 7 casos, inferior en 6 y en 2 no existe registro.

No existe diferencia de sexo (8 varones y $7 \mathrm{mu}-$ jeres).

Gérmenes Gram negativos se identifican en 13 casos, correspondiendo a Aerobacter/Klebsiella el $53,3 \%$.

Los signos y síntomas encontrados corresponden a lo descrito en la literatura.

El hemograma revela desviación a izquierda en
8 casos y más de $20 \%$ de baciliformes en relación al número total de neutrófilos en 7 casos.

EI antibiótico más usado fue la Gentamicina asociada a alguna penicilina.

La letalidad global fue de $26,7 \%$.

Se plantean las medidas tendientes a mejorar el pronóstico de esta patologia.

\section{REFERENCIAS}

I Pierog, S., y Nigarn, S. Neonatal Sepsis. Pediatrics Annals, febrero: 64. 1976.

${ }^{2}$ Wilson, H. D.; Eichentuald, H. F. Sepsis del neonato. Clínica Pediátrica de N. A., agosto: $571,1974$.

${ }^{3}$ Gotoff, S. O,; Bechrman, R. E. Neonatal Septicemia. J. Pediats., 76: 142, 1970.

${ }^{4}$ Zelodo, M. Infecociones hacterianas neonatales. Pediatría (Stgo.) 19: 253, 1976.

5 Buetow, K. C.; Klein, S.W., and Lune, R. B. Septicemia in premature infants. Amer. J. Dis. Child., $110: 29,1965$.

${ }^{6}$ Krugman, S.; Ward, $\boldsymbol{R}$. Enfermedades infecciosas. Ed. Intera. mericana, México, 1974.

7 Givek, L.; Wood, I.F.; Fousek, M. Septicernia of the newborn. Pediat. Clin. N. A. 13: 1131, 1966.

${ }^{8}$ Miller, T. C. Clinic. Ped. X. A. Agosto: 501, 1977.

"Ibarra, L.; Puentes, O,; Beca.J. P. Trabajo presentado a VII Jornadas Anuales de Pediatria, Antofagasta, 1979.

${ }^{10}$ Herkovic, P.; Celdres, V, Beca, J. P.; Hoveard, J.; Román, C. Septicemia por KJebsiella enterobacter en $\mathbf{R}$. N. Rev. Chil. Ped. 50: 37, 1979.

11 Diaz, A. Sepsis del R. N. Pediatria (Stgo.) 12: 179, 1964.

12 Herkovic, P.; Toso, A.; Beco, J. P.; Donoso, E. Etiologfa de las infecciones bacterianas neonatales. Rev. Chil. Ped. 50: 42, 1979.

13 Oppiger, W.; Vargas, L.; Carrillo, D.; Pino, R. El hemograma en las infecciones del R. N. Rev. Chil. Ped. 50: 17, 1979.

14 Larquía y col. Manual de neonatología IL. Ed. H. J. Bujan iBs. As.), 1976.

15 Zelada, M., y Bacigalupo, N. Test para seleccionar el neonato con alto riesgo de infecxión intrauterina Rey. Chil. Ped. 49: 27,1978 . 